\title{
Innovation Technologies in Student's Independent Activity and Creativity Development: The Case of Medical Education
}

\author{
https://doi.org/10.3991/ijet.v14i11.10341 \\ Nurila A. Maltabarova, Alexey I. Kokoshko, Aigul A. Abduldayeva ${ }^{(\varpi)}$, \\ Nasrulla A. Shanazarov, Galiya T. Smailova \\ Astana Medical University, Astana, Kazakhstan \\ abdulaevaa@yahoo.com
}

\begin{abstract}
Adaptive learning technologies that imply the application of supportive symbols and signals allow developing professional and communicative competency, as well as shaping creative abilities of students. This article provides assessment criteria for preliminary, formative, midpoint and summative assessments. This article creates a case for using supportive notes by students during the independent activity in the Emergency Medical Service class. The methodology is novel, as it implies the following way of learning - as an effective means of independent activity organization, notes were written not by teachers but by students. This method can be useful as an alternative recording technique. Accordingly, innovative learning (in our case, independent learning) is one of the main components of education. The statistics have revealed that students gain better subject knowledge with this learning technology.
\end{abstract}

Keywords-Innovation education; creative abilities; supportive symbol; supportive note; pre-course activity.

\section{Introduction}

Information systems are currently an integral part of almost every process that occurs in the environment [1]. Innovation technologies are designed to function within the information systems. These technologies channel the development of all socioeconomic systems (education system included) and are based on data gained from the information flows $[2,3]$. In education, innovation technologies appeal to independent learning [4].

Studies on various issues that surround the independent activity of medical students touch upon the following aspects:

- Teaching and learning trends: Reproductive education [5], subject knowledge delivery [6], the underdeveloped culture of thinking, verbal-logical thinking [7, 8]

- Mental adaptation issues: Zeer and Symanyuk have described in detail the crises of professional development. These crises were pre-divided into standard (common) 
crises (arise in the event of professionalization) and non-standard crises (are caused by psycho-traumatic factors, accidental or unfavourable circumstances) [9]

- Personal habits of preparing for classes: When a student prepares for the learning process, he/she draws one's attention to the features of teaching, communication skills of future specialists, to the assessment technology [10]. He/she may be concerned with individualisation models, which are built up from various modules (general professional module, special module, independent activity module, research module, clinical experience module) [11]. Students also have the use of creativity and innovation $[12,13]$

- Innovations: Innovative curricula design, supportive notes [14], distance learning and its impact on the quality of education [15], portfolio method [16], competencybased approach [17], responsive management system [18, 19], ICTs [20-22]

- Moral development issues: Learning progression [23], methods for fostering an ethical-deontological culture in Latin classes [24], digital games - a powerful learning environment for moral development [25]

- An informal approach to teaching (museum - an informal platform for teaching) [26]

In innovative education, medical students should learn by a new model of education that would fit the healthcare industry [27, 28].

We distinguish three levels of analytical skills development in medical students, who handle innovation technologies (Figure 1):

1. Low level is characterized by the lack of motivation and initiative when it comes to analytical activity; analytical skills are passive

2. Average level - the student is able to manage analytical activity in order to achieve a narrow goal; he/she applies particular analytical techniques

3. High level - the student has mastered the analytical skill. He/she is motivated and initiative

In this regard, the learning process should be organized so that independent activity could serve as both a means of cognitive activity organization and a leading learning mode. In the second case, it would contribute to the acquisition of fundamental knowledge and to the development of thinking. Thus, independent activity (IA) organization turns out to be a pressing issue.

Modern technologies allow stimulating student's activity and teaching rational ways of learning. They also contribute to differentiation.

Thus, various research areas are being developed to investigate the independent activity of studens. Researchers consider both the fundamental principles of independent learning and the specific elements of its mechanism. At the same time, some issues remain understudied, such as issues regarding the specific methods and tools for independent activity.

Thus, the aim of this research is to create a case for using supportive notes by students during the independent activity in the Emergency Medical Service class. 


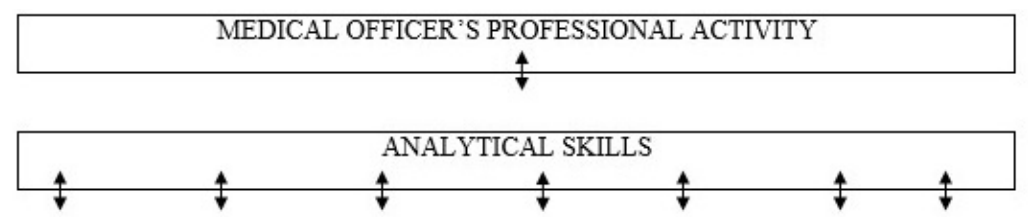

\begin{tabular}{|l|l|l|l|l|l|l|}
\hline $\begin{array}{l}\text { Projecting } \\
\text { Skills }\end{array}$ & $\begin{array}{l}\text { Mobilizing } \\
\text { Skills }\end{array}$ & $\begin{array}{l}\text { Information } \\
\text { Skills }\end{array}$ & $\begin{array}{l}\text { Development } \\
\text { Skills }\end{array}$ & $\begin{array}{l}\text { Communication } \\
\text { Skills }\end{array}$ & $\begin{array}{l}\text { Practical } \\
\text { Skills }\end{array}$ & $\begin{array}{l}\text { Self- } \\
\text { Reflection } \\
\text { Skills }\end{array}$ \\
\hline FUNCTIONAL ACTIVITY: \\
Disease prevention; \\
Disease diagnosis; \\
Diagnosis and first-aid treatment in case of medical emergencies; \\
Medical maintenance by applying therapeutic and surgical methods; \\
Working capacity examination; \\
Forensic medical examination; \\
Medical attendance in case of epidemic outbreak. \\
\hline
\end{tabular}

Fig. 1. Innovation Technologies in Medical Student's Independent Activity Organization

\section{Materials and Methods}

The research was conducted in the Astana Medical University (Anaesthesiology \& Reanimatology Department; Emergency Medical Service Course) in the period from 2014 to 2017. The research involved 2657 fifth-year students of the Faculty of General Medicine.

Control group: 1590 students, who were writing traditional notes during the independent work with methodological literature and ICTs.

Main (research) group: 1067 students, who were writing supportive notes.

A supportive note is a note written using supportive signals or association symbols that replace a certain semantic meaning. A supportive note allows the student to restore the previously known and understandable information instantly.

Basic principles of a supportive note:

- Brevity (300-400 printed characters)

- Structured form (4-5 links, logical blocks)

- Semantic emphasis (frames, block separation, original symbol arrangement)

- Unification of printed characters, autonomy (each of four or five blocks should be independent)

- Associativity

- Ease of retrieval

- Visibility [29] 
The supportive note requires an accurate and understandable interpretation. In other words, if one draws a graphic symbol and explains why it should be associated with a particular material, then both the symbol and the material will be memorized immediately. Therefore, the problem of explaining and memorizing boils down to the creation of a supportive signal for each fragment of the learning material. Supportive signals, if tied together on the background of some cause-and-effect relationship, form a single system that can be used to explain the learning material [30, 31].

We have conducted a statistical analysis of preliminary, formative, midpoint and summative assessments in order to get a comprehensive estimate of knowledge survival (how much independently gained knowledge left there).

Preliminary, formative, midpoint and summative assessments were taken according to modern assessment scoring system:

- 90-100 points - deep and complete knowledge of the learning material and conceptual framework. The student easily takes a cue from the gained knowledge and is able to connect theory with practice, solve practical problems, express and substantiate one's opinions. The highest point value is given for a competent logical answer and for a high-quality note design

- 75-89 points - complete knowledge of the learning material and the conceptual framework. The student takes a cue from the gained knowledge and applies it to solve problems mindfully. His/her answer is competent, but its content and form require correction

- 50-74 points - the basics. His/her narration is incomplete and illogical. He/she makes mistakes when defining the concepts and applying the knowledge to solve problems. The student is unable to prove his/her opinion

- 1-49 points - fragmental and unsystematic knowledge. The student is not able to identify the essentials. He/she makes mistakes when defining the concepts, thereby, twisting their meanings. The narration is disordered and doubtful. The student is unable to apply knowledge to solve problems

- 0 points - complete misunderstanding of material or refusal to answer $[5,31]$

The knowledge survival was assessed at stage I of the end-of-course assessment (computer-based testing). The question base consisted of 500 questions, 25\% thereof were of the category I (memorization), 25\% - of the category II (understanding) and $50 \%$ - of the category III (application). A computer program automatically generated a survey database of 100 questions. The assessment criterion was the number of correct answers in each category.

\section{$3 \quad$ Results and Discussions}

We applied an adaptive learning technology when teaching the Emergency Medical Service (EMS) Course. This technology acts as a mechanism for system coordination and correlation of prerequisites and post-requisites. The students were asked to design mind maps using the supportive symbols and signals, which they developed in accordance with the Shatalov's method [31]. 
The core of the Shatalov's system is the method of supportive signals or milestones - the main content is illustrated on the board using framed keywords, dates, geographical names, etc., connected by arrows, accented with underscores, etc.

Methodological novelty is that the mind maps were designed directly by students.

The introduced learning method, which is based on the use of supportive symbols and signals, is designed to activate student's thinking. The supportive note activates associative thinking.

The goal of our method is (1) to teach students how to diagnose and treat people in case of emergency, and (2) to teach the CPR strategy and tactics. The objectives that follow this goal are below.

Development objective it to shape clinical thinking. This can be done through the analysis of information in the supportive notes, through the comparison of subjective and objective data, and through the identification of treatment priorities, CPR stages and rules. Other two related objectives are to develop cognition and to shape independent behaviour.

Educational objectives are to:

- Cultivate politeness, sensitivity, communication culture

- Develop leadership skills

- Increase focus, develop accuracy and observance skills that are essential for designing the mind maps

The preliminary assessment results do not differ significantly between groups.

Formative assessment was carried out at the time when lessons overlapped with the thematic plan. According to the Five Year Education Program, Thematic Plan, designed for the Faculty of General Medicine, provides 405 academic hours for the Emergency Medical Service (EMS) Course. At this point, only 135 hours are provided for IA (33.3\% of the learning process).

Midpoint assessment was carried out at the end of each block, while the summative assessment - at the end of the course. Assessment results are presented in Table 1.

Table 1. Assessment Results in Control and Research Groups

\begin{tabular}{|l|c|c|c|}
\hline \multicolumn{1}{|c|}{ Group } & Formative Assessment & Midpoint Assessment & Summative Assessment \\
\hline Main & $76 \pm 7$ & $82 \pm 5^{*}$ & $84 \pm 4^{*}$ \\
\hline Control & $71 \pm 5$ & $72 \pm 4$ & $73 \pm 3$ \\
\hline$* \mathrm{p}<0.05$ - reliability is calculated in relation to the control group & \\
\hline
\end{tabular}

The average formative scores do not differ significantly between groups. At the same time, there are significantly higher midpoint and summative point values in the main group ( $\mathrm{p}<0.05$ ). Thus, supportive notes with coding symbols contributed to a deeper understanding of the material.

Assessment data analysis showed that the main group scored $88 \pm 7$ points on average, while the smallest score was 71 points. In the control group, the average score was $78 \pm 5$ points, while the smallest -56 . Thus, adaptive learning technologies that imply the application of supportive symbols and signals allowed us to improve the subject knowledge of students $(\mathrm{p}<0.05)$. A statistical analysis of assessments was 
Paper-Innovation Technologies in Student's Independent Activity and Creativity Development ...

conducted on question categories to analyze the knowledge structure more comprehensively (Table 2).

Table 2. Assessment Results in Control and Research Groups

\begin{tabular}{|l|c|c|c|}
\hline \multirow{2}{*}{\multicolumn{1}{c|}{ Group }} & \multicolumn{3}{|c|}{ Question Category } \\
\cline { 2 - 4 } & I-memorization & II-understanding & III-application \\
\hline Research & $86 \pm 7$ & $89 \pm 5^{*}$ & $89 \pm 4^{*}$ \\
\hline Control & $81 \pm 5$ & $75 \pm 4$ & $74 \pm 3$ \\
\hline
\end{tabular}

${ }^{*} \mathrm{p}<0.05-$ reliability is calculated in relation to the control group

In the main group, there were significantly higher scores in the second and third categories. This indicates that our methodology allows students to learn the material and then apply it in practice more effectively.

\section{Conclusion}

This article creates a case for using supportive notes by students during the independent activity in the Emergency Medical Service class.

This article outlines the principles and features of supportive notes: brevity, structured form, semantic emphasis (frames, block separation, original symbol arrangement), unification of printed characters, autonomy (each of four or five blocks should be independent), associativity, ease of retrieval, visibility.

This article provides the assessment criteria for preliminary, formative, midpoint and summative assessments.

We have tested our learning method on supportive notes that were written directly by students as part of an independent activity.

We have proved that midpoint and summative scores are significantly higher in the main group $(\mathrm{p}<0.05)$. Thus, supportive notes with coding symbols contributed to a deeper understanding of the material.

In the main group, scores in the second and third question categories were significantly higher. This indicates that our methodology allows students to learn the material and then apply it in practice more effectively.

Thus, adaptive learning technologies that imply the application of supportive symbols and signals allow developing the subject and communicative competencies, as well as shaping the creative abilities of students. Besides, this method can be useful as an alternative recording technique.

Accordingly, innovative learning (in our case, independent learning) is one of the main components of education.

\section{$5 \quad$ References}

[1] Galliers, R.D., Leidner, D.E. (2014). Strategic information management: challenges and strategies in managing information systems. Routledge.

[2] Charlton, R. (2000). Innovations in medical education. Medical education, 34(1): 77. 
Paper-Innovation Technologies in Student's Independent Activity and Creativity Development ...

[3] Triola, M.M., Hawkins, R.E., Skochelak, S.E. (2018). The Time Is Now: Using Graduates' Practice Data to Drive Medical Education Reform. Academic medicine: Journal of the Association of American Medical Colleges, 93(6): 826-828. https://doi.org/10.1097/acm.0000000000002176

[4] Serra, E., Beaulé, P., Gofton, W. (2016). Independent learning versus mentorship with the introduction of new surgical skills: a pilot study. Bone Joint J., 98(SUPP 20): 24.

[5] Tolpayev, V.A., Muzenov, Sh.A., Ivanova, E.F., Sinelnikov, M.B. (2001). Psychopedagogical problems of the knowledge assessment scoring system. University news. Northcaucasian region. Social sciences series, 3: 119 - 121.

[6] Guseltseva, M.S. (2006). The category of culture in Psychology and Humanities. Psychology Issues, 4: 3-14 (in Russian).

[7] Rusina, A.V. (1997). Scoring system for assessing learning outcomes. Fundamentals of higher education psychology and pedagogy, pp. $52-60$.

[8] Vyazovova, O.V. (2001). The knowledge assessment scoring system organization. Informatics and Education, 4: 40 - 44.

[9] Nartova-Bochaver, S. (2001). Psychology of personality and interpersonal relations. Moscow: EKSMO-Press, pp. 416.

[10] Horber, D., Langenau, E.E., Kachur, E. (2014). Teaching and Assessing Doctor-Patient Communication Using Remote Standardized Patients and SKYPE: Feedback from Medical Residents Online Submission.

[11] Dmitriyeva, D.D. (2012). Axiological basics of individual educational trajectory formation of medical students (on the Example of Studying Russian as a Foreign Language). Science and school, 5: 103-105.

[12] Higgs, J., Boud, O. (1991). Self-directed learning as part of the mainstream of physiotherapy education. Australian Journal of Physiotherapy, 37: 245-251. https://doi.org/10.1016/s0004-9514(14)60545-6

[13] Aichouni, M., Touahmia, M., Al-Ghamdi, A., Ait-Messaoudene, N., Al-Hamali, R.M., AlGhonamy, A., Al-Badawi, E. (2015). Creativity and Innovation among Gifted Saudi Students - An Empirical Study. Procedia - Social and Behavioral Sciences, 195: 1371 - 1379. https://doi.org/10.1016/j.sbspro.2015.06.403

[14] Ferris, H.A. (2015). The Use of Small Group Tutorials as an Educational Strategy in Medical Education. International Journal of Higher Education, 4(2): 225.

[15] Morozova, N.V. (2011). Innovative means of student's independent activity organization. Young Scientist, 2(2): 102-104 (in Russian).

[16] Sangrador, C.O., Perez, C.V., de Dios, J.G., Baandera, F.H., Guerrero, S.M. (2016). Continuum, the continuing education platform based on a competency matrix. Anales de Pediatría (English Edition), 84(4): 238. e1-238. e8 https://doi.org/10.1016/j.anpede.2015.12.001

[17] Al-Qahtani, M.F., Alsunaid, H., Aljasser, M., Almansour, R., Alharbi, A. (2011). Evaluation of the Current Health Information Management and Technology Program: Students and Faculty Perspectives "Arabic Abstracts. Journal of Taibah University Medical Sciences, 2(6): A6. https://doi.org/10.1016/s1658-3612(11)70180-9

[18] Rattanamethawong, V., Sinthupinyo, S., Chandrachai, E.A. (2015). An Innovation System that can Quickly Responses to the Needs of Students and Alumni. Procedia-Social and Behavioral Sciences, 182: 645-652. https://doi.org/10.1016/j.sbspro.2015.04.801

[19] Amornkitpinyo, T., Wannapiroon, P. (2015).Causal relationship model of the technology acceptance process of learning innovation in the 21 st century for graduate students. Procedia-Social and Behavioral Sciences, 174: 2090-2095.

https://doi.org/10.1016/j.sbspro.2015.02.006 
Paper-Innovation Technologies in Student's Independent Activity and Creativity Development ...

[20] Charles, B.A., Issifu, Y. (2015). Innovation in education: Students' perceptions of implementing ICT in learning in second-cycle institutions in Ghana. Procedia-Social and Behavioral Sciences, 197: 1512-1519. https://doi.org/10.1016/j.sbspro.2015.07.103

[21] Shen, Z., Chen, L., Lui, W., Lv, X., Xiang, G. (2016). Evaluation of faciocutaneous clues to systemic diseases: A learning module for Chinese undergraduate medical students. Dermatologica Sinica, 34(2): 83-87. https://doi.org/10.1016/j.dsi.2015.10.005

[22] Riegle, S.E., Frye, A.W., Glenn, J., Smith, K.L. (2012). Assessing Medical Students' Moral Judgment over the Course of a Four-Year Professionalism and Humanism Curriculum. Online Submission.

[23] Gorghiu, G., Anghel, G.A., Ion, R.M. (2015). Students' Perception Related to a Responsible Research and Innovation Demarche. Procedia-Social and Behavioral Science, 180: 600-605. https://doi.org/10.1016/j.sbspro.2015.02.166

[24] Kebaetse, M. B., Nkomazana, O., Haverkamp, C. (2014). Integrating eLearning to Support Medical Education at the New University of Botswana School of Medicine. Electronic Journal of e-Learning, 12(1): 43-51.

[25] Kropacheva, M.L. (2011). Fostering Ethical and Deontological Culture in Medical Students. Bulletin of Kalashnikov ISTU, 2(50): 219-221.

[26] Schrier, K. (2010). Designing Games for Ethics: Models, Techniques and Frameworks: Models, Techniques and Frameworks. IGI Global. https://doi.org/10.4018/978-1-60960$\underline{120-1}$

[27] Baizak, U., Kudabayev, K., Dzhazdykbayeva, M., Assilbekova, G., Baizakova, B., Mintassova, A. (2017). Competency-based Approach to the Assessment of Professional Training for a Medical Student to Work with Medical Equipment.International Journal of Emerging Technologies in Learning (iJET),12(06): 108-119. https://doi.org/10.3991/ijet.v12i06.7008

[28] Almasi, M., Zhu, C. (2018). Students' Perceptions of Social Presence in Blended Learning Courses in a Tanzanian Medical College. International Journal of Emerging Technologies in Learning (iJET), 13(09): 107-122. https://doi.org/10.3991/ijet.v13i09.8566

[29] Mazhitaeva, Sh., Khan, N.K. (2013). Supportive notes: problems of optimization and algorithmic presentation. Actual problems of humanities and natural science, 8: 285-287.

[30] Banyen, W., Viriyavejakul, C., Ratanaolarn, T. (2016). A blended learning model for learning achievement enhancement of Thai undergraduate students.International Journal of Emerging Technologies in Learning (iJET),11(04): 48-55.

https://doi.org/10.3991/ijet.v11i04.5325

[31] Shatalov, V.F. (2006). Pedagogical skill (video course). Moscow: Center for the MoscowSaint-Petersburg program implementation.

\section{Authors}

Nurila A. Maltabarova - Candidate of Medical Sciences, Professor of the Department of Emergency Medical Care and Anaesthesiology, Reanimatology, JSC «Astana medical university», Astana, Kazakhstan.

Alexey I. Kokoshko - Candidate of Medical Sciences, Docent of the Department of Emergency Medical Care and Anaesthesiology, Reanimatology, JSC «Astana medical university», Astana, Kazakhstan. 
Aigul A. Abduldayeva - Candidate of Medical Sciences, Professor of the Department of preventive medicine and nutrition, JSC «Astana medical university», Astana, Kazakhstan.

Nasrulla A. Shanazarov - Doctor of Medical Sciences, Professor of the the Department of Surgery №2, JSC «Astana medical university», Astana, Kazakhstan.

Galiya T. Smailova - Candidate of Medical Sciences, Assistant Professor of the Department Internal Diseases №2, JSC «Astana medical university», Astana, Kazakhstan.

Article submitted 2019-02-19. Resubmitted 2019-04-15. Final acceptance 2019-04-15. Final version published as submitted by the authors 